\title{
Catalytic conversion of beech wood pyrolytic vapors
}

\author{
Alexandre Margeriat, Alissa Bouzeggane, Chantal Lorentz, Dorothée Laurenti*, \\ Nolven Guilhaume, Claude Mirodatos, Christophe Geantet, Yves Schuurman \\ IRCELYON - UMR 5256 CNRS - Université Lyon 1 Claude Bernard, 2 Avenue Albert Einstein, F-69626 Villeurbanne Cedex, France
}

\begin{abstract}
Catalytic fast pyrolysis (CFP) of beech wood chips was undertaken in a laboratory-scale fixed bed reactor equipped with a biomass semi-continuous dispenser. During pyrolysis, chars are retained on a quartz frit and the pyrolytic vapors are entrained through a fixed-bed catalyst to be converted. Several acidic catalysts such as zeolites H-Beta, zeolite HMFI and 5\% Ni supported on HMFI were screened in this equipment. The Ni/HMFI catalyst was also tested in the presence of 1 vol. $\%$ of hydrogen in the feed stream. Mass and carbon balances were carefully checked and the gas, liquids and solids fractions were analyzed in-depth to evaluate the impact of the catalyst compared to thermal conversion. In the presence of a catalyst, with a low catalyst-to-biomass ratio of 0.1 , a lower amount of bio-oil was formed but it contained less oxygen. The bio-oils were characterized by bidimensional GC (GCxGC) coupled with MS and FID detectors. The amount of gaseous products also increased in the presence of all catalysts. In addition of the deoxygenation, gel-permeation chromatography (GPC) showed a decrease of the highest molecular masses in the bio-oil after catalytic treatment, which confirms the conversion of some oligomers. The presence of $\mathrm{Ni}$ enhanced the deoxygenation reactions while the addition of $\mathrm{H}_{2}$ is also beneficial to the bio-oil composition.
\end{abstract}

\section{Introduction}

Rising energy demand requires new available energy sources that can be efficiently converted into fuels $[1,2]$. Biomass and bio-residues can be converted to more valuable and renewable energy forms via different thermochemical processes including pyrolysis [3]. For many years, conventional pyrolysis, using high temperatures $\left(500-800{ }^{\circ} \mathrm{C}\right)$, has been applied to charcoal production [4] but it is only during the last 30 years that fast pyrolysis was developed. The concept is the rapid heating of biomass at a temperature around $500{ }^{\circ} \mathrm{C}$ with short reaction times of up to $2 \mathrm{~s}$ in an oxygen-free environment to optimize the yield of liquids [3,5-9]. However, pyrolytic bio-oils contain a significant amount of reactive oxygenated species and they need to be stabilized and subsequently deeply deoxygenated to be compatible with traditional fossil fuels [10-13]. A mild hydrogenation step was first proposed to stabilize the bio-oil, in which the most reactive components such as small carboxylic acids are converted $[14,15]$. However high pressure catalytic treatment can also be used [16]. This first stage constitutes an expensive part of the process due to hydrogen consumption and it can also give rise to new heavy molecular weight compounds originating mostly from glucose and its conversion products [17]. Therefore, alternative pathways, allowing a partial deoxygenation before vapor condensation, have been explored such as catalytic fast pyrolysis (CFP) [18-21]. For instance, biomass fluidized catalytic cracking (BFCC) process was proposed with mesoporous or zeolitic catalysts [22-25] and later on industrialized by KiOR but tumbled into bankruptcy. Another strategy consists on the impregnation of a catalyst precursors on the biomass $[26,27]$, and a wide variety of catalytic precursors has been investigated [28-31], but it has to face the problem of catalyst consumption and its regeneration. A third route is using a catalytic bed located after the pyrolysis stage to convert the vapors before condensation [32-34]. In the first strategies, the catalyst is in direct contact with the biomass at the required pyrolysis temperature (often higher than the classical catalytic temperature used) and usually high catalyst-to-biomass ratios are required [35-38]. In the second case, the catalytic reactor can be heated at a different temperature than the pyrolysis reactor and only the pyrolytic vapors are in contact with the catalyst which allow to decrease the catalyst-to-biomass ratio. It has also the advantage of preventing the interactions with ashes since filters can be introduced to separate these solids. Therefore, this second configuration seemed to us very attractive since it allows to screen catalytic solids independently of the pyrolysis step, whereas the catalyst is never in contact with ashes, which can impair the catalyst activity.

Since 2007, the number of publications concerning pyrolysis combined with a catalytic conversion of the vapors has increased drastically and various catalysts were tested. Interesting results were obtained with

\footnotetext{
* Corresponding author.

E-mail address: dorothee.laurenti@ircelyon.univ-lyon1.fr (D. Laurenti).
} 
nickel phosphides which enhanced deoxygenation compared to $\mathrm{Ni}$ / $\mathrm{SiO}_{2}, \mathrm{Pd} / \mathrm{C}$ and acidic materials [39] in the presence of $\mathrm{H}_{2} . \mathrm{Na}_{2} \mathrm{CO}_{3} /$ $\mathrm{Al}_{2} \mathrm{O}_{3}$ [40], supported $\mathrm{MgO}$ [41], $\mathrm{TiO}_{2}$ nanorods, $\mathrm{CeOx}-\mathrm{TiO}_{2}$ mixed oxides, pure $\mathrm{CeO}_{2}, \mathrm{ZrO}_{2}$, and $\mathrm{MgO}$ [42] were also reported to enhance the conversion of pyrolytic vapors. However, zeolites are often considered as the most efficient catalysts and the numerous screening led to identify ZSM-5 zeolite as one of the most active catalysts for deoxygenation, taking into account the yield of liquid [24,32,43-45]. Further, the addition of metal on various zeolites was reported to improve the conversion of pyrolytic vapors. For instance, comparison between ZSM-5 zeolites and ZSM-5-supported metal catalysts (Ga [46], Mo-Cu [47], Fe, Zr, Co [48], Co [49]) always showed an increase in the liquid yield or, interestingly, the enhancement of the selectivity to aromatic, hydrocarbon and naphthalene derivatives. As regards to the oxidation state of the supported metal, the comparison between $\mathrm{Ni}$ in metallic and oxide forms supported on ZSM- 5 showed a convergence of activity during experiments, which was explained by the reduction of $\mathrm{NiOx} /$ ZSM-5 catalyst under the biomass pyrolytic vapors containing $\mathrm{H}_{2}$ and $\mathrm{CO}$ [50]. However, most of the time in all those previous works, the catalyst-to-biomass ratio is still quite high (0.5-20 in wt.) and should be reduced to get a viable catalytic process.

In this work, we carried out the catalytic conversion of beech chips pyrolytic vapors using H-Beta and HMFI (Mobil five equivalent to ZSM5) zeolite catalysts and a Ni/HMFI supported catalyst in a laboratoryscale continuous fixed bed reactor with a cumulated catalyst-to-biomass ratio of 0.1 . The effect of catalyst was investigated by in depth characterization methods of the different obtained fractions comparing with thermal conversion without catalyst. The effect of gas vector atmosphere was also investigated by addition of $1 \%$ vol. $\mathrm{H}_{2}$ to the inert atmosphere in the presence of a $5 \% \mathrm{Ni}$ catalyst on HMFI-90.

\section{Materials and methods}

The starting biomass material consists in beech tree chips with a size of 2-3 mm purchased from J. Rettenmaier \& Söhne (JRS). It has been characterized by elemental analysis (Table 1 ) and thermogravimetric analysis (TGA) under $\mathrm{O}_{2}$ which indicated $2.8 \mathrm{wt} \%$ of mineral components (Fig. S1 in Supplementary material). TGA measurement also performed under $\mathrm{N}_{2}$, showed that $17 \mathrm{wt} \%$ of non-volatile residues were formed after heating the beech wood up to $1000{ }^{\circ} \mathrm{C}$. The solvents $\left(\mathrm{CH}_{2} \mathrm{Cl}_{2}\right.$, Acetone) were purchased from Carlo Erba Reagents ( $\left.\geq 99.8 \%\right)$ and used without any further purification. The zeolites H-Beta and HMFI-90 were provided by Grace and CTI, respectively. HMFI-90 stands for the $\mathrm{SiO}_{2} / \mathrm{Al}_{2} \mathrm{O}_{3}$ molar ratio, i.e. it corresponds to an atomic $\mathrm{Si} / \mathrm{Al}$ ratio of 45 . The zeolite powders were crushed and sieved to reach particle diameter in the range $100-300 \mu \mathrm{m}$. The BET surface area was $707 \pm 2$ for H-Beta and $422 \pm 2$ for HMFI-90 with Si/Al ratio of 16.5 and 40 , respectively.

The higher heating value (HHV) in $\mathrm{MJ} \mathrm{kg}^{-1}$ was estimated for the starting biomass and the bio-oils according to Dulong's formula [51]:

$\mathrm{HHV}=0.3383 \mathrm{C}+1.422(\mathrm{H}-\mathrm{O} / 8)$

Table 1

CHONS elemental analysis and ashes for beech biomass.

\begin{tabular}{|c|c|c|}
\hline \multicolumn{2}{|c|}{ Chemical element } & \multirow{2}{*}{$\begin{array}{l}\text { Mass composition (\%) } \\
46.3 \pm 2\end{array}$} \\
\hline Carbon & $\mathrm{C}$ & \\
\hline Hydrogen & $\mathrm{H}$ & $6.3 \pm 0.1$ \\
\hline Oxygen & $\mathrm{O}$ & $36.1 \pm 2$ \\
\hline Nitrogen & $\mathrm{N}$ & $0.1 \pm 0.1$ \\
\hline \multicolumn{2}{|c|}{ HHV (MJ kg ${ }^{-1}$ ) according Dulong Formula } & 18.2 \\
\hline \multicolumn{2}{|c|}{ Ashes (at $1000^{\circ} \mathrm{C}$ ) from TGA under $\mathrm{O} 2$} & $2.8 \pm 0.2$ \\
\hline \multicolumn{2}{|c|}{ Water } & $8 \pm 1$ \\
\hline
\end{tabular}

Where $\mathrm{C}, \mathrm{H}, \mathrm{O}$ are the mass percentage of carbon, hydrogen and oxygen, respectively, obtained by elemental analysis (Table 1).

\subsection{Preparation of catalysts}

H-Beta and HMFI zeolites were used directly after in situ calcination at $500{ }^{\circ} \mathrm{C}$ for 60 min under $\mathrm{N}_{2}$ in the pyrolysis set up. This step removes the adsorbed water present in the micropores of the zeolites, and hence, allows a better estimation of the mass balance in the experiments.

A $5 \% \mathrm{Ni} / \mathrm{HMFI}-90$ catalyst was prepared by incipient wetness impregnation. The nickel precursor was $\mathrm{Ni}\left(\mathrm{NO}_{3}\right)_{2} \cdot 6 \mathrm{H}_{2} \mathrm{O}$ and after maturation and drying, the catalyst was calcined at $550{ }^{\circ} \mathrm{C}$ before an in situ reduction at $500{ }^{\circ} \mathrm{C}$ during $1 \mathrm{~h}$ under $10 \% \mathrm{H}_{2} / \mathrm{N}_{2}(500 \mathrm{~mL} / \mathrm{min})$. The experimental loading of Ni measured by ICP analysis was $4.9 \mathrm{wt} \%$. After the experiment, the catalysts were recovered and the amount of deposited organic compounds was determined by elemental analyses.

The specific surface areas and pore volume and distribution were measured by nitrogen physisorption using a 3-Flex surface characterization analyzer (Micromeritics) allowing low P/P0 adsorption measurements $\left(10^{-9}\right.$ relative pressure range for $\left.\mathrm{N}_{2}\right)$ and the characterization of micro- and meso-porosity.

\subsection{Pyrolysis-Catalysis reactor system (Fig. 1)}

The woody biomass, previously dried in oven at $110^{\circ} \mathrm{C}$, is stored in a hopper kept under a nitrogen flow of $6 \mathrm{Lh}^{-1}$. Beech tree chips were introduced with a good accuracy at the top part of a $30 \mathrm{~cm}$ long reactor tube by mean of a solid powder dispensing system (Parimix). Inside the reactor, a stainless steel inlay with staggered blades allows to slow down and distribute the wood in the pyrolysis volume (Fig. 1). Wood chips fall in a pit machined in a rotating cylinder and by choosing the frequency of the rotation, the charge injected is known accurately and controlled, after calibration of the device. Every $18 \mathrm{~s}, 100 \mathrm{mg}$ of wood chips were dropped into the reactor maintained at $500{ }^{\circ} \mathrm{C}$. In a typical $1 \mathrm{~h}$ experiment, the total amount of wood reacted was approximately $19 \mathrm{~g} \pm 1 \mathrm{~g}$. The main reactor consists of a quartz tube containing two porous quartz frits, the first frit allows retains the char and unconverted wood in order to protect the catalyst supported on the second frit (Fig. 1). $2 \mathrm{~g}$ of catalyst are used in each experiment. A nitrogen flow of $24 \mathrm{Lh}^{-1}$ is fed at the reactor inlet, resulting in a total nitrogen flow of $30 \mathrm{Lh}^{-1}$ through the catalyst bed, which is placed directly under the pyrolysis reactor and maintained between $458{ }^{\circ} \mathrm{C}$ and $468{ }^{\circ} \mathrm{C}$ depending of the exothermicity/ endothermicity of the occuring reactions. In some experiments, $1 \mathrm{vol} \%$ of hydrogen was added in the $\mathrm{N}_{2}$ flow. A catalyst-to-biomass ratio of 1:10 was used. At the reactor outlet, the vapors are condensed in a trap at $4{ }^{\circ} \mathrm{C}$ where the main part of the bio-oil is collected. This condenser is followed by an electrostatic trap to capture the finest oil droplets. A final trap of silica gel protects the micro-GC used for on-line gas analysis. The liquid effluents were characterized by CHONS analysis, Gel-permeation chromatography (GPC), and GCxGC with MS or -FID detectors.

The reproducibility of the mass balance (bio-oil + gases + solid residues) was evaluated by performing at least three similar runs with beech wood in the absence of catalyst. The catalytic experiments were repeated at least two times. The accuracy of the measurements/data mass balance were evaluated at $0.05 \mathrm{wt} \%$ for the char, $1.5 \mathrm{wt} \%$ for gas analysis, $5 \mathrm{wt} \%$ for the bio-oil and aqueous phase.

\subsection{Products recovery procedure}

The bio-oils formed by pyrolysis of beech wood are viscous and tend to stick to the glassware. A protocol was developed to recover the biooils while minimizing the losses. After pyrolysis, all glassware parts were washed with dichloromethane in order to recover all the fractions. Then, the organic and aqueous phases were separated in a separating funnel. After decantation, the organic phase was evaporated under 


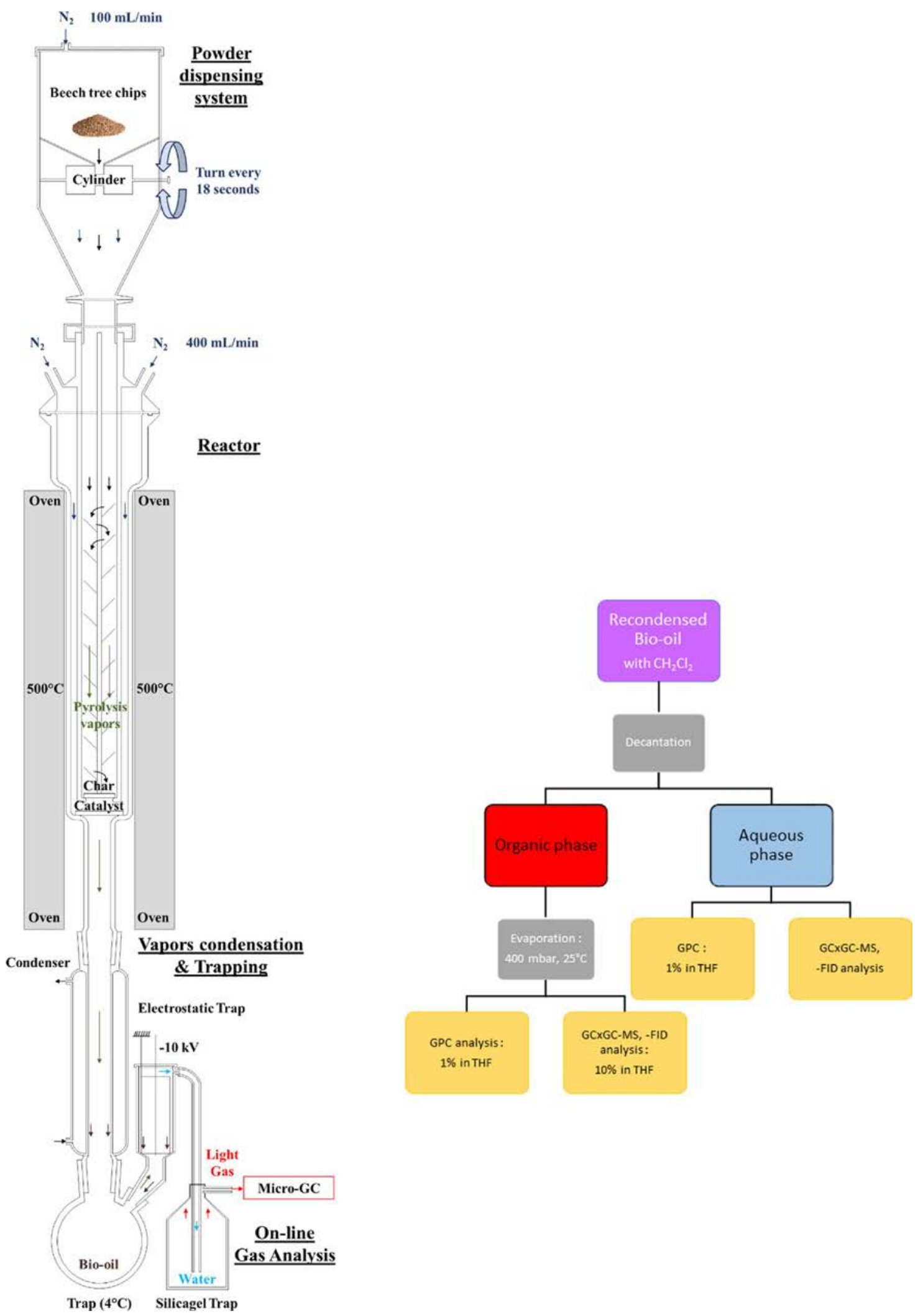

Fig. 1. Pyrolysis catalysis reactor system developed in this work and product recovery protocol.

$400 \mathrm{mbar}$ at $25^{\circ} \mathrm{C}$ to remove the dichloromethane before analysis. Decane was added in the bio-oils samples as internal standard for $\mathrm{GC} \times \mathrm{GC}$ analysis. As seen by CHONS elemental analysis, the aqueous phase contains less than $5 \mathrm{wt}$.\% of carbon, essentially due to carboxylic acids (acetic acid) and sugars as indicated by GCxGC.

\subsection{Transmission electronic microscopy}

An FEI TITAN ETEM G2 $80-300 \mathrm{kV}$ instrument equipped with an objective Cs aberration corrector has been used for the observations of the catalyst (point to point resolution $0.12 \mathrm{~nm}$ ) either in bright field or 
Table 2

N2 adsorption BET surface area and pore volumes of the catalysts (DFT method).

\begin{tabular}{llll}
\hline Catalysts & BET surface area $\mathrm{m}^{2} \mathrm{~g}^{-1}( \pm 2)$ & $\begin{array}{l}\text { Total pore } \\
\text { volume (DFT } \\
\text { method) } \\
\mathrm{cm}^{3} \mathrm{~g}^{-1}\end{array}$ & $\begin{array}{l}\text { t-plot } \\
\text { micropores } \\
\text { volume } \mathrm{cm}^{3} \mathrm{~g}^{-1}\end{array}$ \\
\hline HBeta & 707 & 0.33 & 0.26 \\
HMFI-90 & 422 & 0.18 & 0.17 \\
$5 \%$ Ni/ & 393 & 0.18 & 0.15 \\
$\quad$ HMFI- & & & \\
\hline 90 & & & \\
\hline
\end{tabular}

HAADF dark field mode. The microscope was also equipped with an energy-dispersive Xray (EDX) analyzer (SDD X-Max $80 \mathrm{~mm} 2$ from Oxford Instruments) used for local elemental chemical analysis. The powdered sample was embedded in a resin that was then cut using an ultramicrotome and deposited on a copper grid.

\subsection{Micro-GC}

An online micro-GC was used for online analysis of the gas phase. It is equipped with three different analytical modules and thermal conductivity detectors (Table S2, in SI). A Molsieve column with a Plot U pre-column analyses the permanent gases and $\mathrm{CO}$, a Plot $\mathrm{U}$ column quantifies $\mathrm{CO}_{2}$ and light alkanes and alkenes $\left(\mathrm{C}_{2}\right.$ to $\left.\mathrm{C}_{3}\right)$, and the third Alumina column with a pre column Alumina quantifies $C_{2}$ to $C_{5}$ hydrocarbons. The total analysis duration is $3 \mathrm{~min}$, allowing to perform 25 analyses during a pyrolysis experiment.

\section{6. $G C \times G C-M S /-F I D$}

The GC $\times$ GC set-up was built from an Agilent GC 6890N with a cryogenic modulator (liquid $\mathrm{N}_{2}$ ) from Zoex Corporation (USA) and has been previously described [52,53]. The set of columns installed was a reverse mode proposed for the analysis of phenols and oxygenates in coal derived liquids [54]. This installation is also equipped with two detectors in parallel, an FID and a quadrupole MS detector (Agilent 5975B). The raw signal is a time-ordered series of second dimension chromatograms and it is transferred to GC Image ${ }^{\mathrm{TM}}$ software with the value of the modulation period, which constructs a two dimensional chromatogram by placing the two chromatograms side by side. Identification is accomplished by cross referencing the measured mass spectra to the spectra in the available MS libraries. Quantification was done with FID analysis taking into account an effective carbon number for each family of compounds relatively to decane as internal standard [55].

\subsection{Gel-permeation chromatography (GPC)}

Analyses were performed by using an Agilent apparatus (1200 series) equipped with two PL gel columns (50 and $500 \AA$ ) and a differential refractive index (DRI) detector. Analyses were carried out at $35^{\circ} \mathrm{C}$ using THF as eluent at a flowrate of $1 \mathrm{~mL} / \mathrm{min}$. Bio-oil samples were dissolved at around $1 \mathrm{wt} \%$ in THF before injection. The GPC system was calibrated with polystyrene standards with molecular weights from 162 to $55,100 \mathrm{gmol}^{-1}$. Depicted chromatograms were normalized according the highest peak.

\subsection{CHONS elemental analysis}

Elemental analyses were performed on a Flash 2000 apparatus from Thermo-scientific. A known mass - with a micron precision- of sample is introduced in a little tin basket whose the combustion is very exothermic. A fast combustion at very high temperature (until $1800{ }^{\circ} \mathrm{C}$ ) is produced in the oven flowed by helium when the sample and an optimum quantity of oxygen are injected. After an immediate catalytic conversion to avoid parasite reactions in this reactive mixture, combustion gas $\left(\mathrm{N}_{2}, \mathrm{CO}_{2}, \mathrm{H}_{2} \mathrm{O}, \mathrm{SO}_{2}\right)$ are driven in a chromatography column to separate these compounds. Then they are detected and quantified by a thermal conductivity detector (TCD). Based on the reproducibility of the measurements, the accuracy was evaluated at \pm 2 for $\mathrm{C}$ and $\mathrm{O}, \pm 0.1$ for $\mathrm{H}$ and $\mathrm{N}$.

\section{Results and discussion}

\subsection{Characterization of the catalysts}

The textural properties of the catalysts used in this study are summarized in Table 2. H-Beta zeolite has the largest surface area $\left(707 \mathrm{~m}^{2} \mathrm{~g}^{-1}\right)$. The addition of Ni on HMFI-90 decreased only slightly the surface area from 422 to $392 \mathrm{~m}^{2} \mathrm{~g}^{-1}$, whereas the pore volume was similar, indicating that Ni impregnation does not affect much the textural properties of HMFI-90. Transmission electron microscopy in HAADF mode ( $\mathrm{Z}$ contrast) reveals the presence of relatively well dispersed $\mathrm{Ni}$ nanoparticles in the $5 \% \mathrm{Ni} / \mathrm{HMFI}-90$ catalyst (Fig. 2), but the $\mathrm{Ni}$ particle size distribution is broad as illustrated by the images taken at different magnifications. Particles sizes in the $1.6-9 \mathrm{~nm}$ range are observed, with a few large aggregates.

\subsection{Mass and carbon balances during catalytic pyrolysis experiments}

The reactor system developed in this work combining a thermal pyrolysis step and the catalytic treatment of pyrolytic vapors (Fig. 1), allowed us to obtain various organic bio-oils with and without catalyst (thermal pyrolysis). These bio-oils are viscous and tend to stick in the condenser and in the three traps (cold, electrostatic and silicagel). Using dichloromethane to wash the different glassware parts and to extract organic compounds from the aqueous phase, allowed to recover a maximum amount of liquid products and the mass balance closures in these experiments (Fig. 3) varied between 95-101\%, which can be considered as satisfactory considering the complex procedure requested to recover the solid, liquid and gaseous products. The amount of gaseous compounds ranged from 34 to $44.5 \%$ and was lowest in the thermal experiment. This amount is above what is usually observed for thermal experiment and can be attributed to the reactor design. As shown in Fig. 3, the yield in bio-oil obtained in a thermal experiment (no catalyst) was close to $32 \%$, whereas the aqueous fraction represented $14 \mathrm{wt} \%$ of the initial biomass. The use of a zeolite catalyst under similar operating conditions led to a decrease in the bio-oil yield while the yields in aqueous and gas phases increased. These tendencies are even enhanced in the case of Ni/HMFI-90 catalyst with and without $1 \%$ of $\mathrm{H}_{2}$, suggesting that the role of metal is crucial.

In all the experiments, the amount of solid residues remaining on the first frit was roughly constant (around $18 \mathrm{wt} . \%$ ) and close to the amount of non-volatile residues (17 wt.\%) found in TGA measurements under $\mathrm{N}_{2}$. Our reactor design prevents the deposition of ashes on the catalysts, which was shown to have a significant impact on its performance [56].

The carbon balance was assessed for thermal and 5\%Ni/HMFI-90 catalyzed experiments (Fig. 4). The carbon closure is close to $93 \%$ for thermal experiment and decreased to $88 \%$ for the catalyzed experiment. A tentative explanation can be related to the loss of volatile components, present in higher quantity in catalyzed experiments, during the products recovery procedure. In both experiments, the char represented $\approx 32 \%$ of the total amount of carbon, this similar amount is in agreement with the fact that the char is formed in the wood pyrolysis process and that the catalyst placed downstream does participate in this reaction step. Apart from the solid residue, in the thermal experiment most of the carbon was found in the organic phase (34.4\%) and in the 

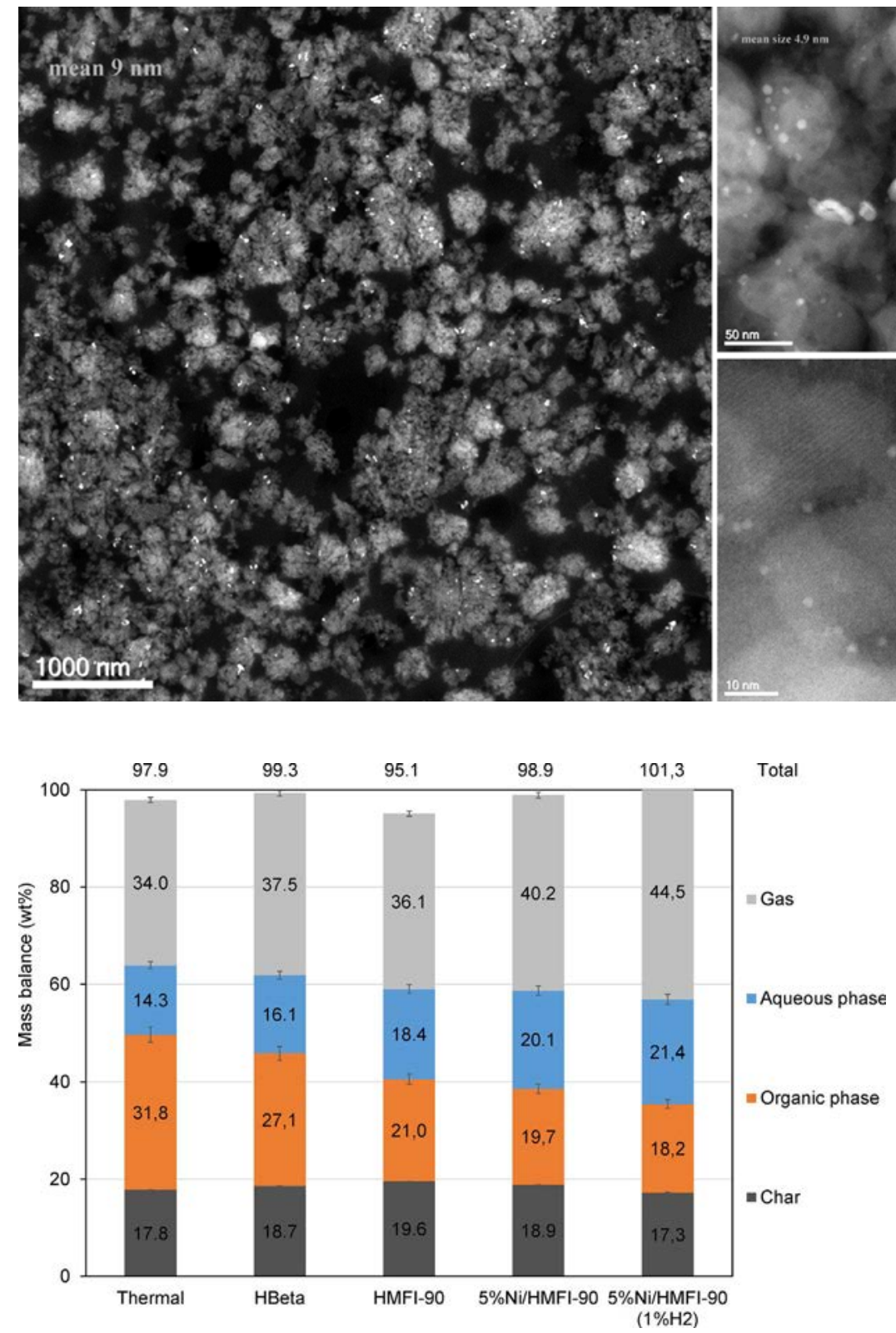

Fig. 2. HAADF STEM analysis of $5 \% \mathrm{Ni} / \mathrm{HMFI}-90$ sample under various magnification.

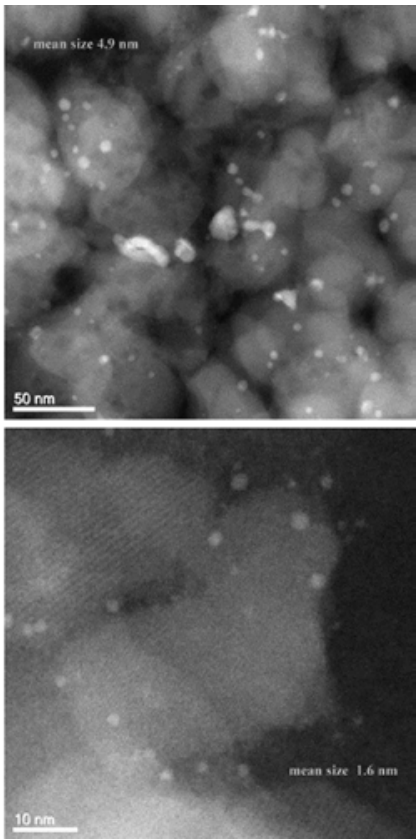

Fig. 3. Yields (wt\%) of the different produced fractions for the thermal and catalytic experiments.

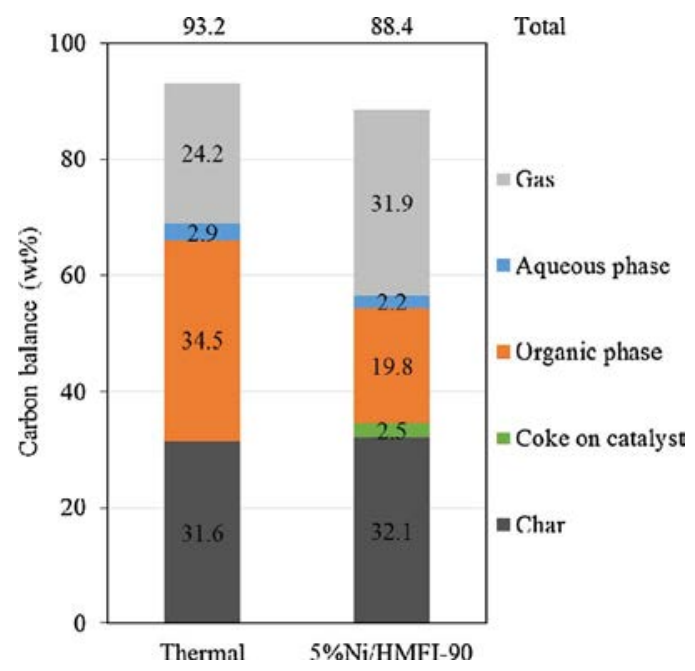

Fig. 4. Carbon balance for thermal and 5\% Ni/HMFI-90 experiments. gas phase as light hydrocarbons (24.2\%). The aqueous fraction contained only little carbon (2.9\%), which suggests that the $\mathrm{CH}_{2} \mathrm{Cl}_{2}$ extraction was efficient to remove most of the water-soluble molecules from the aqueous phase. In the catalytic experiment using $5 \% \mathrm{Ni} / \mathrm{HMFI}-$ 90 , the carbon was essentially found as gaseous compounds and the organic phase represented comparatively a lower amount of carbon. The carbon content in the aqueous phase was also low, as well as the amount of carbon deposited on the catalyst. The main difference between thermal and catalytic pyrolysis was the increase in gaseous products, which were clearly formed at the expense of the organic fraction. The elemental composition and properties of the bio-oils obtained after thermal or catalytic treatment of vapors over HMFI-90 and $\mathrm{Ni} / \mathrm{HMFI}-90$ catalysts are summarized in Table 3 . The most interesting feature is the strong decrease of oxygen content and $\mathrm{O} / \mathrm{C}$ atomic ratio using the HMFI-based catalysts. O content was decreased to $26-29 \%$ compared to $43 \%$ in the thermal experiment and the resulting $\mathrm{O} / \mathrm{C}$ ratio was decreased to 0.3 . The calculated HHV for the bio-oils were thus increased to $26-27 \mathrm{MJ} \mathrm{kg}^{-1}$ instead of $18 \mathrm{MJ} \mathrm{kg}^{-1}$ for the initial biomass. 
Table 3

Elemental composition and HHV of the bio-oils in the absence and presence of a catalyst.

\begin{tabular}{|c|c|c|c|c|c|c|c|}
\hline Bio-oils & $\mathrm{C} \% \pm 2$ & $\mathrm{H} \% \pm 0.1$ & $\mathrm{~N} \% \pm 0.1$ & $\mathrm{O} \% \pm 2$ & $\begin{array}{l}\mathrm{O} / \mathrm{C} \\
\text { at. } \\
\text { ratio }\end{array}$ & $\begin{array}{l}\mathrm{H} / \mathrm{C} \\
\text { at. } \\
\text { ratio }\end{array}$ & $\begin{array}{l}\mathrm{HHV} \\
\left(\mathrm{MJ} \mathrm{kg}^{-1}\right)\end{array}$ \\
\hline Thermal & 49.3 & 7.2 & 0.2 & $43.3^{*}$ & 0.66 & 1.75 & 19.2 \\
\hline HMFI-90 & 66 & 7 & 0.2 & 26.4 & 0.30 & 1.27 & 27.6 \\
\hline $\begin{array}{c}\text { 5\%Ni/ } \\
\text { HM- } \\
\text { FI- } \\
90\end{array}$ & 63.6 & 6.8 & 0.3 & $29.3^{*}$ & 0.35 & 1.28 & 26.0 \\
\hline
\end{tabular}

(*deduced value).

\subsection{Characterization of gaseous products}

The gas composition obtained by $\mu$-GC on-line analysis is illustrated in Fig. 5 for each experiment. $\mathrm{CO}_{2}$ and $\mathrm{CO}$ were the main compounds formed in all experiments. $\mathrm{C} 1\left(\mathrm{CH}_{4}\right)$ to $\mathrm{C} 5$ alkanes $(\mathrm{C} 2+)$ and $\mathrm{H}_{2}$ were formed simultaneously. The overall composition of the gas phase did not change deeply depending on the presence or absence of catalyst. However, with the metal supported catalyst, a higher amount of hydrogen was formed during the experiment (three-fold), suggesting the possible contribution of the water-gas-shift (WGS) reaction and also, of similar processes than in aqueous phase reforming (APR) well-described by Huber in presence of metallic catalysts [57]. The time dependence of the gas composition during the pyrolysis runs is illustrated in Fig. 6. The $\mathrm{CO}$ production reached a maximum at short reaction time with zeolites and Ni catalysts, and this trend is particularly enhanced with the presence of $1 \% \mathrm{H}_{2}$ in the feed (Fig. 6a). With the pure zeolites, the quantity of CO stabilized after $45-50 \mathrm{~min}$ of reaction to reach the level of thermal pyrolysis, whereas the Ni catalyst with $1 \%$ of $\mathrm{H}_{2}$ produced higher amounts of $\mathrm{CO}$ throughout all the experiment. For $\mathrm{CO}_{2}$, the highest production was observed with the $\mathrm{Ni}$ catalyst with and without $\mathrm{H}_{2}$ addition, whereas the trends are roughly similar for thermal and zeolites-catalyzed experiments (Fig. 6b). The production of $\mathrm{C}_{2} \mathrm{H}_{4}$ was enhanced with all catalysts and particularly with Ni/HMFI-90 with $1 \% \mathrm{H}_{2}$ (Fig. 6c). Hydrogen production was clearly enhanced in the presence of Ni/HMFI-90 catalyst (Fig. 6d) with and without additional $\mathrm{H}_{2}$, up to ten times higher at the beginning of the process compared to thermal or pure zeolites-catalyzed pyrolysis. In the case of experiments run with $1 \%$ additional $\mathrm{H}_{2}$, the inlet $\mathrm{H}_{2}$ amount is displayed as the horizontal black line in Fig. 6d, and shows clearly that the increase of hydrogen production is similar in both cases. However, the formation of $\mathrm{C}_{2} \mathrm{H}_{4}$ and other light hydrocarbons suggests that a complex set of reaction take place, including cracking and dehydrogenation reactions. We can also note that for the Ni/HMFI-90 catalyst in presence of $1 \% \mathrm{H}_{2}$,
$\mathrm{CO}, \mathrm{CO}_{2}$ and $\mathrm{C}_{2} \mathrm{H}_{4}$ productions are still higher than thermal one after $1 \mathrm{~h}$ reaction, contrarily to the other catalysts, which indicates that under these conditions the catalyst was probably not deactivated after $1 \mathrm{~h}$ under reaction. In conclusion, $\mathrm{H}_{2}$ was preferentially formed with zeolite supported $\mathrm{Ni}$ catalyst and the presence of $\mathrm{H}_{2}$ appeared beneficial to prevent the catalyst deactivation.

\subsection{Characterization of liquid products}

An extensive liquid characterization was undertaken as the effect of catalysts on the nature of the bio-oil is the main inquiry in this work. GPC of the organic phase clearly evidenced the decrease in the amount of heavy compounds in the catalytic experiments, compared to the thermal conversion (Fig. 7). For the thermal bio-oil, the average molecular mass was around $400 \mathrm{~g} / \mathrm{mol}$ in PS equivalent, it decreased to 320-370 for catalytic experiments. The polydispersity of macromolecules in the bio-oil was highly reduced using catalysts, although they did not fully inhibit the formation of heavy molecules.

The presence of Ni on zeolite also had a slight impact on the size of the molecular fragments and average $\mathrm{Mw}$, and the addition of $1 \mathrm{vol} . \%$ $\mathrm{H}_{2}$ enhanced this effect, since the lowest $\mathrm{Mw}$ and polydispersity were found for Ni/HMFI-90 with $1 \% \mathrm{H}_{2}$.

The GCxGC analysis of the bio-oil obtained without catalyst with a mass detector (MS) allowed to identify more than one hundred belonging to 4 main families: acids and aldehydes, cyclic oxygenated 5membered ring compounds which are mainly cyclopentanone and furan derivatives, phenols and methylphenols, and methoxyphenols (Fig. 8a). In this work because of the $\mathrm{CH}_{2} \mathrm{Cl}_{2}$ extraction, the benzenediols and sugars were mostly kept in aqueous phase and their quantification in organic phase is quite delicate as only traces were detected; thus, they were included in the large methoxyphenols family. The GCxGC-MS analysis of the bio-oils formed in the presence of catalysts evidenced the appearance of new families of deoxygenated products: benzenes, indenes, naphthalenes, fluorenes and anthracenes (Fig. 8b), which are denoted "deoxygenated" and summarized with the other families in Fig. 9. GCxGC analyses with FID detector were repeated for the same bio-oils, and we used the effective carbon number (ECN) method [55] to calculate an average response factor for all those families, in order to perform a semi-quantitative analysis of the GCxGC-FID chromatograms (Table S1, Suppl. Mater.). Fig. 9 summarizes the selectivities towards the main families of products. Interestingly, the detailed composition of the bio-oils showed that the use of zeolite catalysts led to a decrease in the quantity of oxygenated 5-membered ring compounds (cyclopentanone and furan derivatives), acids and aldehydes, while the yield of methoxyphenols showed a twofold increase, compared to the composition of the thermal bio-oil. This trend was enhanced with Ni supported

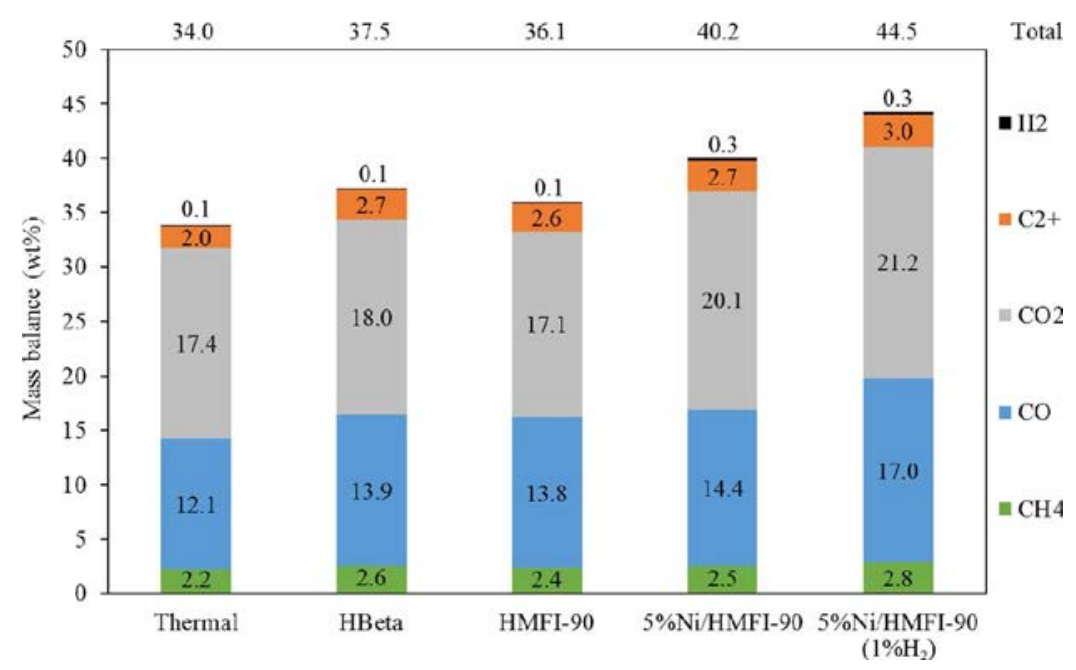



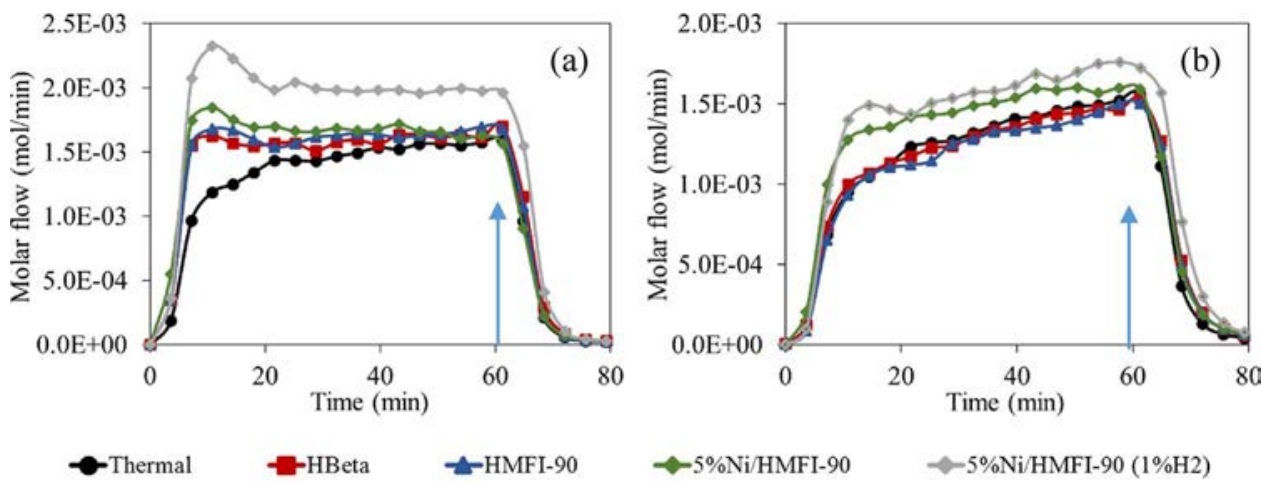

Fig. 6. Evolution of $\mathrm{CO}$ (a), $\mathrm{CO}_{2}$ (b), $\mathrm{C}_{2} \mathrm{H}_{4}$ (c) and $\mathrm{H}_{2}$ (d) during the thermal and catalytic experiments.
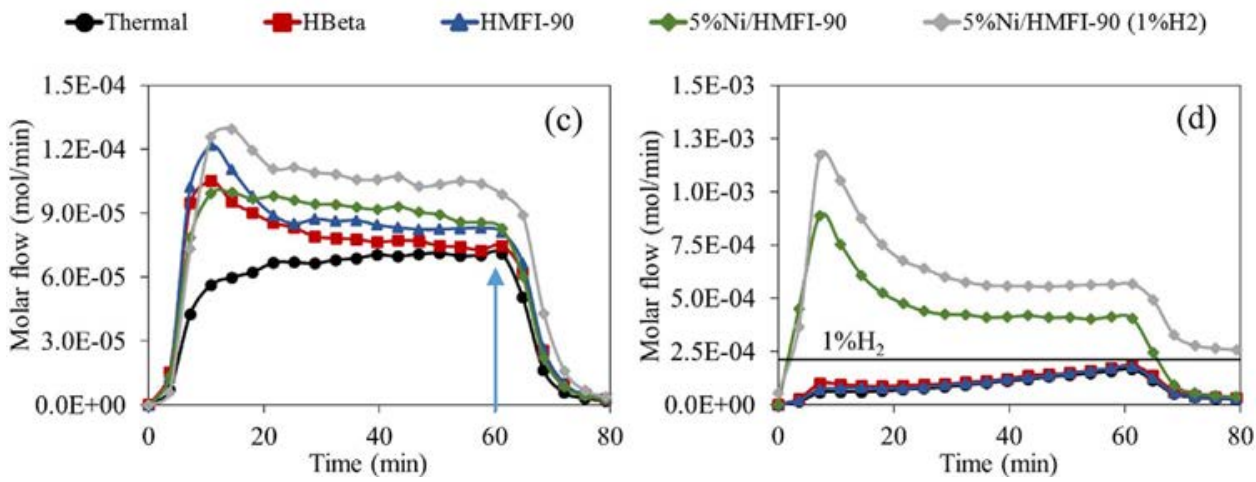

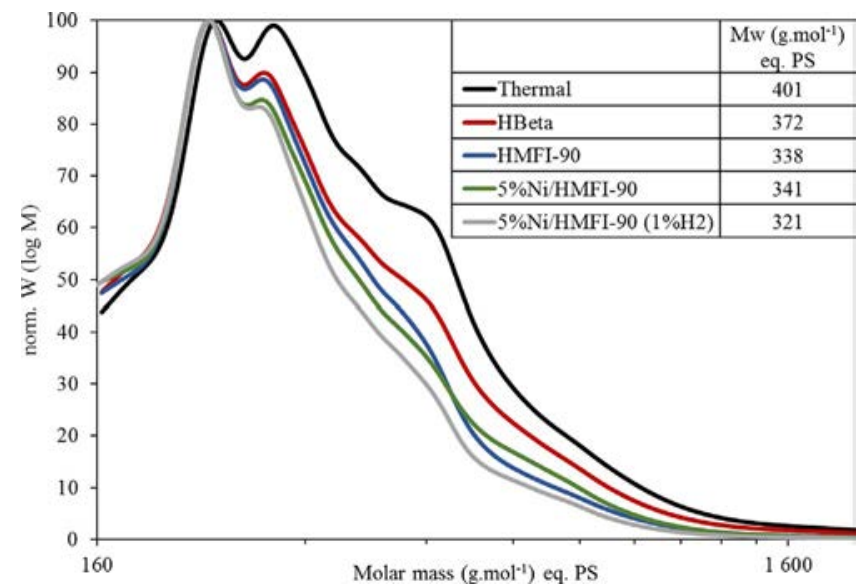

Fig. 7. Gel-permeation chromatography molar mass distribution of the bio-oils (normalized on the highest peak).

on HMFI-90, while the formation of deoxygenated aromatics reached almost $10 \%$ with $\mathrm{Ni}$ catalyst in the presence of $\mathrm{H}_{2}$. The amount of (alkyl)phenols, which can be formed by direct depolymerization of lignin but also by cyclization-aromatization of cellulose and hemicellulose derivatives, did not vary much depending on the presence or absence of catalyst. Phenols are also intermediary formed from methoxyphenols by demethoxylation and possibly further converted to deoxygenated aromatics and naphthenes. Thus the production and consumption of phenols depends of several parameters. The sum of deoxygenated compounds (essentially aromatics), phenols and methoxyphenols, which are the three families originating mainly from lignin depolymerization, globally increased in the presence of catalysts and even more when Ni catalysts were used. However, the GCxGC detection is limited to compounds that can be vaporized, i.e. under $300-350 \mathrm{~g} /$ mol, which means that a large part of the bio-oil is therefore not analyzed by this technique. It has been evaluated by the ECN quantification that $33 \mathrm{wt} \%$ of the bio-oil is analyzed by GCxGC in the case of catalytic runs, while $25 \mathrm{wt} \%$ is analyzed in the case of thermal run. Global techniques like GPC or NMR that can analyze the full extent of molecular weights present in the bio-oils are needed to complete the chromatographic characterization of the bio-oils.

These experiments confirmed that the presence of catalysts (zeolites, $\mathrm{Ni} /$ zeolite) enhanced the conversion of pyrolytic vapors into gaseous and deoxygenated compounds. The $\mathrm{CO}_{2} / \mathrm{CO}$ and light alkanes production increased due to the conversion of light oxygenates (carboxylic acids, aldehydes....) by decarboxylation and/or decarbonylation. The amount of aqueous phase, which was mainly composed of water and contained very few carbon products, increased simultaneously, confirming that deoxygenation also took place by dehydration reactions of the liquid organic products. Additionally, the macromolecules in the bio-oils were converted into smaller fragments in the presence of catalysts, as seen by GPC measurements. These results indicate that the catalysts have also an impact on the depolymerization of the macromolecules, often associated to pyrolytic lignin, remaining in the pyrolytic bio-oils. The use of a Ni/HMFI-90 catalyst enhanced the production of $\mathrm{H}_{2}$ and the deoxygenation reactions leading to aromatics and small alkanes, therefore improving the quality of the condensed bio-oil in terms of oxygen content and average molecular weight. Finally, the addition of $1 \%$ of $\mathrm{H}_{2}$ in the stream had a strong impact on the conversion of heavy molecules into smaller ones as observed by GPC, on the deoxygenation by dehydration and decarboxylation/decarbonylation reactions as observed with gas and water analysis, and furthermore seems to prevent the catalyst deactivation. This is an important fact since the main drawback of this fixed-bed catalytic process, compared to FCC, is the catalyst deactivation, which requires frequent regeneration steps. After $1 \mathrm{~h}$ of reaction, the spent catalysts were analyzed to quantify the carbon and hydrogen contents of the coke deposits (Table 4). The C content was much higher for zeolite H-Beta (19.8 wt. \%) than for HMFI-90 and 5\%Ni/HMFI-90 catalysts, the carbon values measured for the latter solids, being between 11 and $13 \mathrm{wt} . \%$. This could be attributed to coke and/or to physically adsorbed carbon molecules. In order to regenerate the catalyst, we undertook the temperature programmed oxidation (TPO) of the used HMFI-90 catalyst (Figs. S2, SI). The appearance of $\mathrm{CO}_{2}$ and $\mathrm{CO}$ occurred between $350{ }^{\circ} \mathrm{C}$ and $800{ }^{\circ} \mathrm{C}$ together while the decrease of $\mathrm{O}_{2}$ indicates its consumption $\left(10 \% \mathrm{O}_{2}\right.$ in $\mathrm{N}_{2}$ flow). After this TPO, the catalyst was reused and we obtained similar amounts of gas and liquids than with fresh HMFI-90. The GPC (Figs. S3, SI) also confirms the decrease of masses in the 

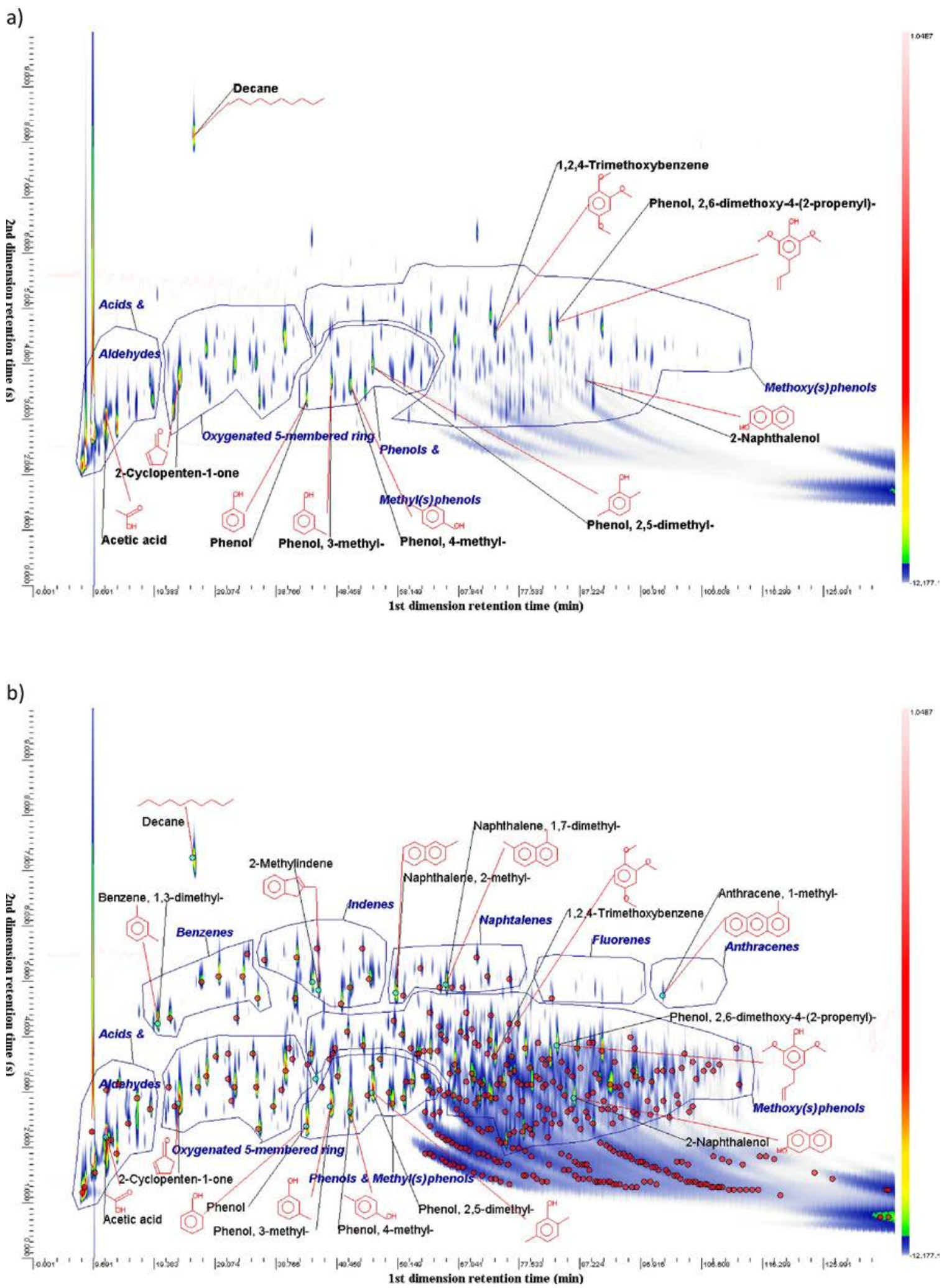

Fig. 8. GCXGC-MS chromatogram a) of thermal pyrolytic bio-oil b) of bio-oil obtained with 5\% Ni/HMFI-90.

organic fraction similarly to fresh catalyst.

Among the 7,7 g of carbon coming from the wood and passing through the catalyst, around $0.25 \mathrm{~g}$ remained on the HMFI and $\mathrm{Ni}$ / HMFI solids. For the same type of catalyst, Yung et al. showed that the presence of Ni led to a decrease in coke deposition on the catalyst [50]. This result was not observed here but real coke and physisorbed carbon deposition were not distinguished. However, the formation of gaseous products at the end of the pyrolysis run was still higher with the $\mathrm{Ni}$ / HMFI catalyst than in the thermal process (Fig. 6), suggesting that the catalyst was still active after $1 \mathrm{~h}$. Longer experiments with Ni catalyst were not performed but they did with HMFI-90 catalyst (not shown); those experiments with higher biomass-to-catalyst ratio, revealed that 


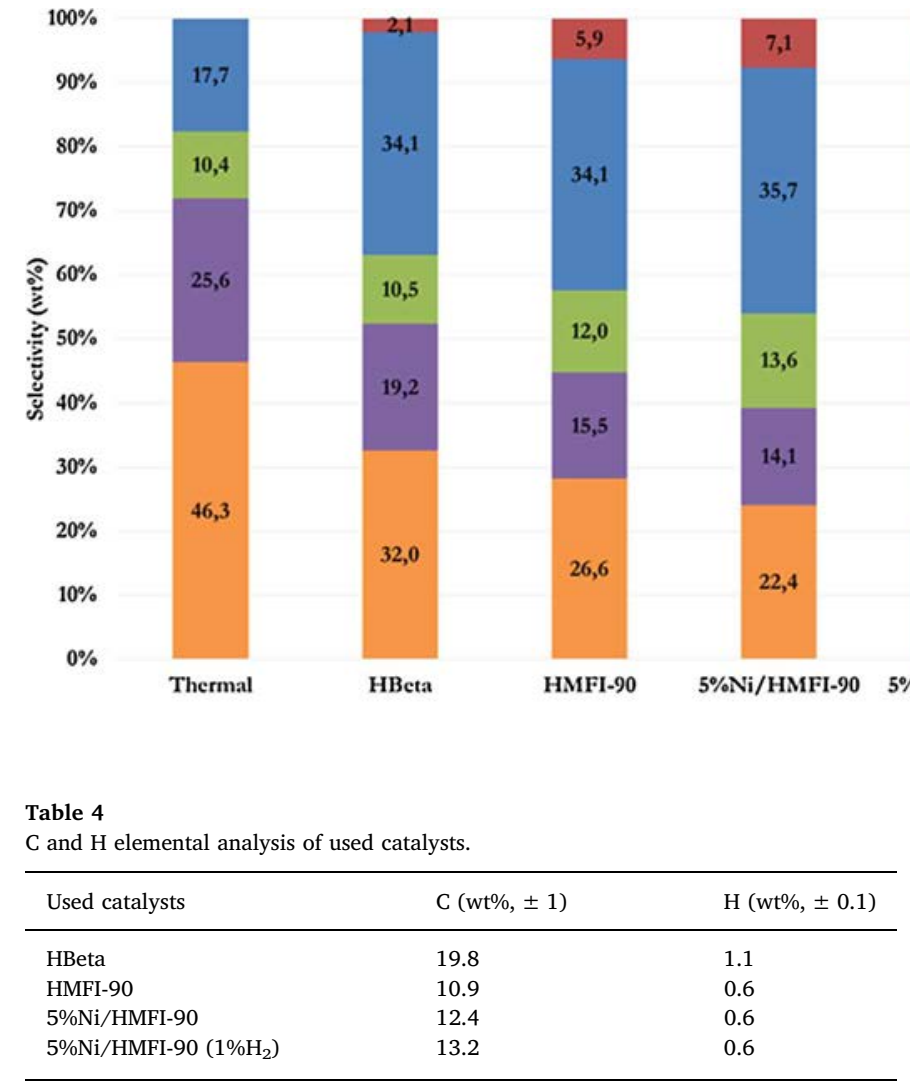

gas evolution and liquid composition were influenced similarly by the catalyst up to $150 \mathrm{~min}$, which could indicated that the catalyst deactivates more slowly than expected and suggested that a lower catalyst/ biomass ratio could be employed in this system. However, Yung et al. [50] showed that the HZSM-5/biomass ratio has a very important effect on the relative amounts of hydrocarbons, furans, phenols and other primary wood vapors products and that at very high catalyst-to-biomass ratios, only deoxygenated hydrocarbons (olefins and aromatics) are formed. Therefore, decreasing the catalyst/biomass ratio might be detrimental to the bio-oil quality, particularly as regards to its oxygen content. Thus the use of metal/zeolite catalyst with a $10 \mathrm{wt} . \%$ catalystto-biomass ratio and in presence of $1 \% \mathrm{H}_{2}$, seems to be the better option to improve the quality of the pyrolytic bio-oil and further investigations on the nature of the metal are in progress.

\section{Conclusions}

In this work, we describe a home-built reactor combining a thermal pyrolysis step and the catalytic processing of the pyrolytic vapors in continuous flow for short reaction time $(1 \mathrm{~h})$. We screened various catalysts based on zeolites and $\mathrm{Ni}$ supported on zeolites and compared the effect of catalysts to a thermal conversion. The presence of catalysts to convert the vapors under inert atmosphere has a deep impact on the bio-oil, aqueous phase, gas yield and compositions. The use of acidic catalysts such as zeolites or Ni supported on zeolite, led to smaller amounts of bio-oils but they were significantly deoxygenated, by decarboxylation/decarbonylation and dehydration/dehydroxylation reactions. Interestingly, the formation of small carbonylic/carboxylic molecules such as aldehydes and acids, which are soluble in the aqueous phase and contribute to the instability of bio-oils, were strongly reduced in the presence of catalysts and thus the quality of the bio-oil was highly improved. Finally the addition of $1 \%$ of $\mathrm{H} 2$ in the feed enhanced the catalytic performances and also should play a role to prevent the catalytic deactivation with $\mathrm{Ni} / \mathrm{HMFI}-90$ solid.
Fig. 9. Selectivities for the products families detected by GCxGC in organic bio-oils for the various catalysts.

\section{Acknowledgments}

The authors are grateful to the French National Research Agency (ANR) for providing funding for this work through the Catapult project (ANR-13-BIME-0005). The coordinator of Catapult project, François Broust from CIRAD (Montpellier, France), is warmly thanked for advices for reactor building. Mimoun Aouine (IRCELYON) is warmly thanked for ETEM characterizations.

\section{Appendix A. Supplementary data}

Supplementary data associated with this article can be found, in the online version, at https://doi.org/10.1016/j.jaap.2018.01.015.

\section{References}

[1] E.M. Rubin, Genomic of cellulosic biofuels, Nature 454 (2008) 841-845.

[2] G.W. Huber, A. Corma, Synergies between bio- and oil refineries for the production of fuels from biomass, Angew. Chem. Int. Ed. 46 (2007) 7184-7201.

[3] A.V. Bridgwater, Review of fast pyrolysis of biomass and product upgrading, Biomass Bioenergy 38 (2012) 68-94.

[4] M.J. Antal, M. Gronli, The Art, Science, and technology of charcoal production, Ind. Eng. Chem. Res. 42 (2003) 1619-1640.

[5] A.V. Bridgwater, G.V.C. Peacocke, Fast pyrolysis processes for biomass, Renew. Sustain. Energy Rev. 4 (2000) 1-73.

[6] S. Czernik, A.V. Bridgwater, Overview of applications of biomass fast pyrolysis oil, Energy Fuels 18 (2004) 590-598.

[7] R.H. Venderbosch, W. Prins, Fast pyrolysis technology development, Biofuels Bioprod. Biorefin. 4 (2010) 178-208.

[8] S. Xiu, A. Shahbazi, Bio-oil production and upgrading research: a review, Renew. Sustain. Energy Rev. 16 (2012) 4406-4414.

[9] W.N.R.W. Isahak, W.M.M. Hisham, M.A. Yarmo, Y.H. Taufiq-yap, A review on biooil production from biomass by using pyrolysis method, Renew. Sustain. Energy Rev. 16 (2012) 5910-5923.

[10] M.C. Samolada, W. Baldauf, I.A. Vasalos, Production of a bio-gasoline by upgrading biomass flash pyrolysis liquids via hydrogen processing and catalytic cracking, Fuel 77 (1998) 1667-1675.

[11] A. Gutierrez, M.E. Domine, Y. Solantaust, Co-processing of upgraded bio-liquids in standard refinery units - fundamentals, Presented at the 15th European Biomass Conference \& Exhibition, Berlin, 7-11 MaY, 2007.

[12] J. Wildschut, J. Arentz, C.B. Rasrendra, R.H. Venderbosch, H.J. Heeres, Catalytic hydrotreatment of fast pyrolysis oil: model studies on reaction pathways for the carbohydrate fraction, Environ. Prog. Sustain. Energy 28 (2009) 450-460.

[13] R.H. Venderbosch, A.R. Ardiyanti, J. Wildschut, A. Oasmaa, H.J. Heeres, Stabilization of biomass-derived pyrolysis oils, J. Chem. Technol. Biotechnol. 85 (2010) 674-686.

[14] D.C. Elliott, Historical developments in hydroprocessing bio-oils, Energy Fuel 21 (2007) 1792-1815.

[15] D.C. Elliott, S.J. Lee, T.R. Hart, Stabilization of Fast Pyrolysis Oil: Post Processing, PNNL Report 21549, (2012).

[16] F. de Miguel Mercader, M.J. Groeneveld, S.R.A. Kersten, C. Geantet, G. Toussaint, N.W.J. Way, C.J. Schaverien, K.J.A. Hogendoorn, Hydrodeoxygenation of pyrolysis oil fractions: process understanding and quality assessment through co-processing 
in refinery units, Energy Environ. Sci. 4 (2011) 985.

[17] M. Ozagac, C. Bertino-Ghera, D. Uzio, M. Rivallan, D. Laurenti, C. Geantet, Impact of guaiacol on the formation of undesired macromolecules during catalytic hydroconversion of bio-oil: a model compounds study, Biomass Bioenergy 95 (2016) $182-193$.

[18] R. French, S. Czernik, Catalytic pyrolysis of biomass for biofuels production, Fuel Proc. Technol. 91 (2010) 25-32.

[19] C. Liu, H. Wang, A.M. Karim, J. Suna, Y. Wang, Catalytic fast pyrolysis of lignocellulosic biomass, Chem. Soc. Rev. 43 (2014) 7594-7623.

[20] G. Yildiz, F. Ronsse, R. van Duren, W. Prins, Challenges in the design and operation of processes for catalytic fast pyrolysis of woody biomass, Renew. Sustain. Energy Rev. 57 (2016) 1596-1610.

[21] D.A. Ruddy, J.A. Schaidle, J.R. Ferrell III, J. Wang, L. Moens, J.E. Hensley, Recent advances in heterogeneous catalysts for bio-oil upgrading via ex-situ catalytic fast pyrolysis catalysts development through the study of model compounds, Green Chem. 16 (2014) 454-490.

[22] A.A. Lappas, M.C. Samolada, D.K. Iatridis, S.S. Voutetakis, I.A. Vasalos, Biomass pyrolysis in a circulating fluid bed reactor for the production of fuels and chemicals, Fuel 81 (2002) 2087-2095.

[23] E. Antonakou, A.A. Lappas, M.H. Nilsen, A. Bouzga, M. Stocker, Evaluation of various types of Al-MCM-41 materials as catalysts in biomass pyrolysis for the production of bio-fuels and chemicals, Fuel 85 (2006) 2202-2212.

[24] A. Aho, N. Kumar, K. Eranen, T. Salmi, M. Hupa, D.Y. Murzin, Catalytic pyrolysis of woody biomass in a fluidized bed reactor: influence of the zeolite structure, Fuel 87 (2008) 2493-2501.

[25] F. Gong, Z. Yang, C. Hong, W. Huang, S. Ning, Z. Zhang, Y. Xu, Q. Li, Selective conversion of bio-oil to light olefins: controlling catalytic cracking for maximum olefins, Bioresour. Technnol. 102 (2011) 9247-9254.

[26] G. Dobele, G. Rossinskaja, T. Dizhbite, G. Telysheva, D. Meier, O. Faix, Application of catalysts for obtaining 1,6-anhydrosaccharides from cellulose and wood by fast pyrolysis, J. Anal. Appl. Pyrolysis 74 (2005) 401-405.

[27] K. Bru, J. Blin, A. Julbe, G. Volle, Pyrolysis of metal impregnated biomass: an innovative catalytic way to produce gas fuel, J. Anal. Appl. Pyrolysis 78 (2007) 291-300.

[28] O. Terakado, A. Amano, M. Hirasawa, Explosive degradation of woody biomass under the presence of metal nitrate, J. Anal. Appl. Pyrolysis 85 (2009) 231-236.

[29] Y. Richardson, J. Blin, G. Volle, J. Motuzas, A. Julbe, In situ generation of Ni metal nanoparticles as catalyst for H2-rich syngas production from biomass gasification, Appl. Catal. A: Gen. 382 (2010) 220-230.

[30] Q. Lu, C.-Q. Dong, X.-M. Zhang, H.-Y. Tian, Y.-P. Yang, X.-F. Zhu, Selective fast pyrolysis of biomass impregnated with $\mathrm{ZnCl}_{2}$ to produce furfural: analytical Py-GC/ MS study, J. Anal. Appl. Pyrolysis 90 (2011) 204-212.

[31] S. Eibner, F. Broust, J. Blin, A. Julbe, Catalytic effect of metal nitrate salts during pyrolysis of impregnated biomass, J. Anal. Appl. Pyrolysis 113 (2015) 143-152.

[32] P.A. Horne, P.T. Williams, Upgrading of biomass-derived pyrolytic vapors over zeolite ZSM-5 catalyst: effect of catalyst dilution on product yields, Fuel 75 (1996) 1043-1050.

[33] T.S. Nguyen, M. Zabeti, L. Lefferts, G. Bremb, K. Seshan, Catalytic upgrading of biomass pyrolysis vapours using faujasite zeolite catalysts, Biomass Bioenergy 48 (2013) 100-110.

[34] W.B. Widayatnoa, G. Guana, J. Rizkianaa, J. Yang, X. Hao, A. Tsutsumi, A. Abudula, Appl. Catal. B: Environ. 186 (2016) 166.

[35] A. Pattiya, J.O. Titiloye, A.V. Bridgwater, Fast pyrolysis of cassava rhizome in the presence of catalysts, J. Anal. Appl. Pyrolysis 81 (2008) 72-79.

[36] C. Torri, M. Reinikainen, C. Lindfors, D. Fabbri, A. Oasmaa, E. Kuoppala, Investigation on catalytic pyrolysis of pine sawdust: catalyst screening by Py-GCMIP-AED, J. Anal. Appl. Pyrolysis 88 (2010) 7-13.

[37] G. Yildiz, T. Lathouwers, H.E. Toraman, K.M. van Geem, G.B. Marin, F. Ronsse, R. van Duren, S.R.A. Kersten, W. Prins, Catalytic fast pyrolysis of pine wood: effect of successive catalyst regeneration, Energy Fuels 28 (2014) 4560-4572.

[38] S. Vichaphund, D. Aht-ong, V. Sricharoenchaikul, D. Atong, Production of aromatic compounds from catalytic fast pyrolysis of Jatropha residues using metal/HZSM-5 prepared by ion-exchange and impregnation methods, Renew. Energy 79 (2015) 28-37.

[39] N. Koike, S. Hosokai, A. Takagaki, S. Nishimura, R. Kikuchi, K. Ebitani, Y. Suzuki, S.T. Oyama, Upgrading of pyrolysis bio-oil using nickel phosphide catalysts, J. Catal 333 (2016) 115-126.

[40] T.S. Nguyen, L. Lefferts, K. Babu, S.S. Gupta, K. Seshan, Catalytic conversion of biomass pyrolysis vapours over sodium-based catalyst: a study on the state of sodium on the catalyst, ChemCatChem 7 (2015) 1833-1840.

[41] S.D. Stefanidis, S.A. Karakoulia, K.G. Kalogiannis, E.F. Iliopoulou, A. Delimitis, H. Yiannoulakis, T. Zampetakis, A.A. Lappas, K.S. Triantafyllidis, Natural magnesium oxide $(\mathrm{MgO})$ catalysts: a cost-effective sustainable alternative to acid zeolites for the in situ upgrading of biomass fast pyrolysis oil, Appl. Catal. B: Environ. 196 (2016) 155-173.

[42] O.D. Mante, J.A. Rodriguez, S.D. Senanayake, S.P. Babu, Catalytic conversion of biomass pyrolysis vapors into hydrocarbon fuel precursors, Green Chem. 17 (2015) 2362-2368.

[43] C. Mukarakate, M.J. Watson, J. ten Dam, X. Baucherel, S. Budhi, M.M. Yung, H. Ben, K. Iisa, R.M. Baldwin, M.R. Nimlos, Upgrading biomass pyrolysis vapors over ß-zeolites: role of silica-to-alumina ratio, Green Chem. 16 (2014) 4891-4905.

[44] Y. Zhao, L. Deng, B. Liao, Y. Fu, Q.-X. Guo, Aromatics production via catalytic pyrolysis of pyrolytic lignins from bio-oil, Energy Fuels 24 (2010) 5735-5740.

[45] M.S. Abu Bakar, J.O. Titiloye, Catalytic pyrolysis of rice husk for bio-oil production, J. Anal. Appl. Pyrolysis 103 (2013) 362-368.

[46] H.J. Park, H.S. Heo, J.-K. Jeon, J. Kim, R. Ryoo, K.-E. Jeong, Y.-K. Park, Highly valuable chemicals production from catalytic upgrading of radiata pine sawdustderived pyrolytic vapors over mesoporous MFI zeolites, Appl. Catal. B: Environ. 95 (2010) 365-373.

[47] Y. Huang, L. Wei, Z. Crandall, J. Julson, Z. Gu, Combining Mo-Cu/HZSM-5 with a two-stage catalytic pyrolysis system for pine sawdust thermal conversion, Fuel 150 (2015) 656-663.

[48] P. Li, D. Li, H. Yang, X. Wang, H. Chen, Effects of Fe-, Zr-, and Co-modified zeolites and pretreatments on catalytic upgrading of biomass fast pyrolysis vapors, Energy Fuels 30 (2016) 3004-3013.

[49] E.F. Iliopoulou, S. Stefanidis, K. Kalogiannis, A.C. Psarras, A. Delimitis, K.S. Triantafyllidis, A.A. Lappas, Pilot-scale validation of Co-ZSM-5 catalyst performance in the catalytic upgrading of biomass pyrolysis vapours, Green Chem. 16 (2014) 662-674.

[50] M.M. Yung, A.K. Starace, C. Mukarakate, A.M. Crow, M.A. Leshnov, K.A. Magrini, Biomass catalytic pyrolysis on Ni/ZSM-5: effects of nickel pretreatment and loading, Energy Fuels 30 (2016) 5259-5268.

[51] T.M. Brown, P. Duan, P.E. Savage, Hydrothermal liquefaction and gasification of Nannochloropsis sp, Energy Fuels 24 (2010) 3639-3646.

[52] G. Toussaint, C. Lorentz, M. Vrinat, C. Geantet, Comprehensive 2D chromatography with mass spectrometry: a powerful tool for following the hydrotreatment of a Straight Run Gas Oil, Anal. Meth. 3 (2011) 2743-2748.

[53] B. Joffres, M.T. Nguyen, D. Laurenti, C. Lorentz, V. Souchon, N. Charon, A. Daudin, A. Quignard, C. Geantet, Lignin hydroconversion on $\mathrm{MoS}_{2}$-based supported catalyst: comprehensive analysis of products and reaction scheme, Appl. Catal. B: Environ. 184 (2016) 153-162.

[54] B. Omais, M. Courtiade, N. Charon, D. Thiébaut, A. Quignard, M.C. Hennion, Investigating comprehensive two-dimensional gas chromatography conditions to optimize the separation of oxygenated compounds in a direct coal liquefaction middle distillate, J. Chromatogr. A 1218 (2011) 3233-3240.

[55] K. Schofield, The enigmatic mechanism of the flame ionization detector: its overlooked implications for fossil fuel combustion modeling, Prog. Energ. Combust. Sci. 34 (2008) 330-350.

[56] G. Yildiz, F. Ronsse, R. Venderbosch, R. van Duren, S.R.A. Kersten, W. Prins, Effect of biomass ash in catalytic fast pyrolysis of pine wood, Appl. Catal. B: Environ. 168-169 (2015) 203-211.

[57] R.R. Davda, J.W. Shabaker, G.W. Huber, R.D. Cortright, J.A. Dumesic, Aqueousphase reforming of ethylene glycol on silica-supported metal catalysts, Appl. Catal. B: Environ. 43 (2003) 13-26. 